\title{
Identification of two QTL influencing upper temperature tolerance in three rainbow trout (Oncorhynchus mykiss) half-sib families
}

\author{
TIMOTHY R. J ACKSON†, MOIRA M. FERGUSON*†, ROY G. DANZMANN†, \\ ANTHONY G. FISHBACK $\dagger$, PETER E. IHSSEN†, MICHAEL O'CONNELL§ \& TERESA J . \\ CREASE $\dagger$ \\ $\dagger$ †epartment of Zoology, University of Guelph, Guelph, Ontario, Canada N1G 2W1, †Ontario Ministry of Natural \\ Resources, Southern Research Station, Box 5000, Maple, Ontario, Canada L6A 1S9 and §Marine Gene Probe Lab., \\ Department of Biology, Dalhousie University, Halifax, Nova Scotia, Canada B3H 4J 1
}

\begin{abstract}
We searched for linkage among 24 polymorphic loci (allozymes, RAPD, microsatellites) in three half-sib backcross families of rainbow trout (Oncorhynchus mykiss) produced by crossing strains divergent for the quantitative trait of upper temperature tolerance. Seven significant and two suggestive pairwise linkage associations between molecular marker loci were observed involving 14 loci clustered into four linkage groups. The association between a pair of allozyme loci (sIDHP-3* and $\left.m M E P-2^{*}\right)$ has been reported previously. Recombination rates varied greatly between the sexes and families. Two quantitative trait loci (QTL) were mapped by detecting a significant association between variance in upper temperature tolerance and alleles at the microsatellite loci Omy325UoG and Ssa14DU. The two QTL appear to reside in different linkage groups and account for $\approx 13$ per cent and 9 per cent of the overall additive genetic variance in upper temperature tolerance. No significant interaction was detected between Omy325UoG and Ssa14DU suggesting that the effects of the QTL are additive.
\end{abstract}

Keywords: linkage mapping, microsatellite, QTL, rainbow trout, temperature tolerance.

\section{Introduction}

Most characters of economic and evolutionary importance are controlled by many loci and are inherited quantitatively (quantitative trait loci, QTL). Cosegregation of phenotypic variation and alleles at marker loci with no presupposed phenotypic effect is one approach to locate chromosomal regions containing QTL (Paterson et al., 1988). The identification of molecular markers tightly linked to QTL allows the direct determination of the effect of QTL on fitness traits (i.e. additivity, epistasis), the number of regions involved and the magnitude of their effects.

Rainbow trout (Oncorhynchus mykiss) is one of several salmonid species of great economic and evolutionary importance. An ancestor to the Salmonidae is believed to have undergone an autotetraploidization event 25-100 million years ago (reviewed by Allendorf \& Thorgaard, 1984). This event led to members of the Salmonidae having

*Correspondence. E-mail: mmfergus@uoguelph.ca twice the DNA per cell (twice the chromosome arm number) as their nearest diploid relatives, the Clupeidae (herrings) and Osmeridae (smelts). The process of 'diploidizing' the duplicate genome has involved centric fusions and fissions which have generally preserved the chromosome arm number in the salmonids while producing variation in the chromosome number between and within species. This genome rearrangement has also resulted in a type of chromosomal assortment during meiosis in males called pseudolinkage. Pseudolinkage is indicated by an excess of recombinant genotypes between paternal alleles at two loci caused by the pairing of ancestral homeologous chromosomal segments at meiosis (Wright et al., 1983).

The current salmonid linkage map is a composite derived from several species and consists of 54 protein-coding (allozyme) loci defining 22 chromosomal arms (May \& Johnson, 1990). We used three half-sib backcross families of rainbow trout produced by crossing strains divergent for the quantitative trait of upper temperature tolerance to search for linkage among 24 polymorphic loci (allo- 
zymes, RAPD, microsatellites). We report four linkage groups two of which are additions of new loci to two known linkage groups. Furthermore, we have located two QTL of major effect controlling upper temperature tolerance. Tolerance to high temperature in fishes, a polygenic trait of broad physiological consequence, may involve de novo synthesis of heat shock proteins (Fader et al., 1994) and the products of MHC isoform genes (Gerlach et al., 1990).

\section{Materials and methods}

\section{Rainbow trout families}

High and low temperature tolerance strains were produced by the Ontario Ministry of Natural Resources (O.M.N.R.), at Maple, Ontario, Canada through a series of selection experiments and random matings (Ihssen, 1986). Hybridizations were conducted in 1973 between a hatchery stock derived from Nottawasaga River, Ontario and two domestic Ontario hatchery strains, the Normandale and Goosens strains. Following these matings, selection for upper 'lethal' temperature tolerance was conducted for three successive generations (Jackson, 1995). These experiments followed the same protocol as that used in selection experiments described below with the exception that individuals intended for broodstock were revived. This resulted in two strains of rainbow trout: one with a low tolerance for high temperature (L) and one with a high tolerance for high temperature $(\mathrm{H})$. The strains were maintained by mating individuals within strains.

In 1991, an H-strain female was crossed to an L-strain male to produce a hybrid family. In January 1993, a hybrid $(\mathrm{H} \times \mathrm{L})$ male, $91-1$, was backcrossed to a female from the parental $\mathrm{H}$ strain, $88-5$, and a female from the parental L strain, 88-1, to produce two experimental backcross families (lot 22, $n=121$ and lot 25, $n=104)$. In April 1993, the hybrid male 91-1 was backcrossed again to a second female from the parental $\mathrm{H}$ strain, $88-30$, to produce a third experimental backcross family (lot $41, n=144$ ).

\section{Upper temperature tolerance experiment}

The progeny from the three backcross families were subjected to upper lethal temperature tolerance experiments at 15-17 months from fertilization. The fish were transferred into the temperature trial aquarium one week prior to the experiment. Test fish were held in a similar aquarium several weeks prior to transfer. Water temperature was raised over $60 \mathrm{~min}$ from ambient $\left(9-10^{\circ} \mathrm{C}\right)$ to the estimated upper lethal temperature for rainbow trout acclimated to $10^{\circ} \mathrm{C}$ which is $25.7^{\circ} \mathrm{C}$ (Ihssen, 1986). Water flow was held constant and dissolved oxygen levels were maintained at a minimum of 80 per cent saturation. When a fish was unable to maintain its equilibrium, the time since reaching $25.7^{\circ} \mathrm{C}$ in min was recorded and considered to be its 'effective time' (ET) in the zone of thermal resistance (Fry, 1971). Individuals were then killed and fork length (length from tip of snout to beginning of fork in the caudal fin), weight and sex (when discernible) were recorded and tissues were sampled. Sex could be distinguished for 76 individuals from lot 22, 66 individuals from lot 25, and no individuals from lot 41 .

\section{Genetic polymorphisms}

DNA was isolated from 50 to $100 \mathrm{mg}$ of muscle or liver tissue from all backcross progeny and their parents according to Bardakci \& Skibinski (1994).

Ten RAPD loci were amplified by PCR as described by Jackson (1995). Oligodeoxynucleotide primers were UBC52, UBC60, UBC66, UBC95 and UBC100 (University of British Columbia, Oligonucleotide Synthesis Laboratory) as well as OPF3 (Operon Technologies). The resulting amplified DNA fragments were separated on 1.2 per cent agarose gels with a $1 \mathrm{~kb}$ ladder (Boehringer Mannheim) as a size standard and visualized by ethidium bromide staining. The genetic nomenclature for RAPD loci includes the primer name followed by the size (in kb pairs) of the representative fragment (dominant phenotype) written in italics.

Nineteen microsatellite loci were amplified by PCR. The genetic nomenclature is a modification of minisatellite nomenclature (Prodöhl et al., 1994). There is an identifier for the species of origin and the genomic library clone number (in italics), followed by an abbreviation for the laboratory responsible for first isolating that locus $(\mathrm{UoG}=\mathrm{Uni}$ versity of Guelph, Canada; DU = Dalhousie University, Canada; INRA = CRJ-INRA, France; and $\mathrm{TUF}=$ Tokyo University of Fisheries, Japan). If one primer set amplifies two disomic loci then a forward slash and a designation of ' 1 ' or ' 2 ' is given for each locus as recommended by Prodöhl et al. (1994). Primers for four new loci are reported in the present study. They are (the locus name is followed by the $5^{\prime}$ primer sequence, the microsatellite core sequence, the $3^{\prime}$ primer sequence and the annealing temperature): Omy272/1UoG and Omy272/2UoG, 5' -CTGTGTGAAGGCATGCAAAGG (GT) ${ }_{15}$ ATTCAGCAGTAGTGGGCTTTAACC-3'，50² ; Omy- 
$301 U o G, 5^{\prime}$-ACTTAAGACTGGCAACCTT (GT) $)_{20}$ CTACACGGCCTTCGGGTGAGA- $3^{\prime}, \quad 54^{\circ} \mathrm{C}$; and Omy335UoG, 5'-ACCTATATCAACTGAATGTATGCC (GT) $)_{37}$ TGGAACAGGCTGGTGAGAGG$3^{\prime}, 54^{\circ} \mathrm{C}$. The other 15 loci have been reported elsewhere. They are: Omy2DU and Omy105DU (Hologene); Omy77DU (Morris et al., 1996); Omy207UoG, Omy325UoG and Ssa293DU (O'Connell et al., 1997); OmyFGT2TUF and OmyFGT3TUF (Sakamoto et al., 1994a,b); Ssa289DU, Ssa14DU and Ssa4DU (McConnell et al., 1995); Ssa85DU (O'Reilly et al., 1996); and Str15INRA, Str60INRA and Str73INRA (Estoup et al., 1993).

The PCR reaction mixture and thermal cycling protocol were based on those described by Estoup et al. (1993). Alleles were separated on 8 per cent polyacrylamide denaturing gels ( $7.83 \mathrm{~m}$ urea) which were autoradiographed for 1-3 days under Kodak Biomax MR film. An M13 sequencing reaction was used as a size standard to approximate the allele size in base pairs (bp).

Genotypes at 36 allozyme loci were collected (sAAT-1,2*, sAAT-4*, $A C P^{*}, A K-1^{*}, A K-2^{*}, A D H^{*}$, $C K-A 1^{*}, C K-A 2^{*}, \quad E S T-2^{*}, \quad b G L U A^{*}, G 3 P D H-1^{*}$, GPI- $A^{*}, G P I-B 1^{*}, G P I-B 2^{*}, I D D H-1 *, I D D H-2 *$, mIDHP-1*, $\quad$ IDHP-2*, SIDHP-3,4*, LDH-A1*, $L D H-A 2^{*}, L D H-B 1^{*}, L D H-B 2^{*}, s M D H-1,2 *, s M D H-$ 3,4*, $m M D H^{*}-1,2, \quad m M E P-1^{*}, \quad m M E P-2^{*}, \quad s M E P^{*}$, $M P I^{*}, P E P A^{*}, P G A M^{*}, P G M-1^{*}, P G M-2^{*}, S S O D^{*}$ and $X D H^{*}$ ) using starch gel electrophoresis (Allendorf et al., 1977).

The phenotypic sex of salmonid fishes is determined by the genotype at a single chromosomal region with males being the heterogametic sex (Hartley, 1987). Therefore, male progeny were designated as heterozygotes and female progeny were designated as homozygotes at the sex-determining locus $(S e x)$.

\section{Statistical analysis}

Neither the originating L nor $\mathrm{H}$ strain was highly inbred so that the parents for the experimental backcrosses were not wholly homozygous (backcross parent) or heterozygous $\left(F_{1}\right.$ parent $)$ for the marker loci examined. In cases where both parents were heterozygous with at least three different alleles between them, segregation was tested in each parent. Progeny data from each parental contribution were tested for goodness of fit to the expected 1:1 segregation of alleles using likelihood ratio $(G)$ statistics. A sequential Bonferroni correction for multiple tests was performed to correct the significance threshold $(P<0.05)$ for the number of $G$-tests executed on the group of loci segregating in each parent (Rice, 1989).

A Visual Basic program, LinkmFex (Danzmann, unpublished) was used to execute the linkage analysis through a series of pairwise comparisons between loci. This program allowed the use of crosses between non-inbred lines for linkage analysis by considering the segregation of each parental complement of alleles separately. It also overcame the complicating factor of pseudolinkage in measuring classical linkage as the program was written to assume that the least abundant pairs of genotypes are the recombinants. The linkage phase within the parents of these crosses was unknown so it was not possible to differentiate pseudolinkage from classical linkage between alleles inherited from the sire. As a result, linkage associations occurring among paternal alleles remain unresolved. Log of Odds ratio (LOD) scores were calculated to determine linkage. A LOD threshold of 3.0 was interpreted as significant and a LOD score between 2.0 and 3.0 was considered 'suggestive' of linkage (Botstein et al., 1980). Because of complete interference in salmonids (Thorgaard et al., 1983), map distance $(x)$ was estimated by $x=\theta$ where $\theta$ is the proportion of recombinants. Standard error was calculated according to Mather (1951).

QTL analysis for chromosomal regions contributing to upper temperature tolerance was performed separately on the maternal and paternal contribution to each family. For the collection of the upper temperature tolerance data, progeny from each of the three half-sib families were subdivided into more than one lethal temperature challenge experiment. The experiments were combined for analysis. In lot 41, only ET data from the first two of four experiments (88 progeny) were used for the QTL analysis because of a lower rearing temperature in the last two experiments (56 progeny). Linear probability plots were used to determine normality of ET distributions in the three backcrosses prior to QTL analysis. Untransformed ET data for lots 22 and 41 and $\log _{10}$ transformed ET data for lot 25 were normally distributed. Associations of individual marker loci with upper temperature tolerance were tested by a two-way analysis of variance (ANOVA) with interaction using the following model:

$Y_{i j k}=\mu+\alpha_{j}+\beta_{k}+\alpha \beta_{j k}+\varepsilon_{i j k}$,

where $Y_{i j k}$ is the ET for the $i$ th individual of the $j$ th genotype in the $k$ th experiment, $\mu$ is the family mean, $\alpha_{j}$ is the portion of $Y_{i j k}$ attributable to genotype, $\beta_{k}$ is the portion of $Y_{i j k}$ attributable to experiment, $\alpha \beta_{j k}$ is the interaction term and $\varepsilon_{i j k}$ is the 
random residual associated with each individual. A significant effect of size on upper temperature tolerance was observed in lots 22 and 41 through a regression between fork length and ET (lot 22, slope $=-0.040$ and $P=0.031 ;$ lot 41 , slope $=$ -0.033 and $P=0.029)$. Fork length was added to the above model in these two families as a covariate resulting in a two-way analysis of covariance (ANCOVA):

$Y_{i j k}=\mu+\alpha_{j}+\beta_{k}+\alpha \beta_{j k}+c\left(X_{i j k}-X\right)+\varepsilon_{i j k}$,

where $c$ is the regression coefficient of $Y$ on $X, X_{i j k}$ is the fork length for individual $i$ with genotype $j$ from experiment $k$ and $X$ is the fork length grand mean. ANOVAS and ANCOVAS were performed through the ANOVA function in SYSTAT. The genotype $R^{2}$ for each model (genotype SS/total SS) was used to determine the proportion of within-family variance in mean ET accounted for by an apparent molecular marker association with upper temperature tolerance. The sequential Bonferroni test was used to correct the significance threshold $(P<0.05)$ for the multiple tests performed.

Epistatic relationships (i.e. interaction) between pairs of marker loci associated with upper temperature tolerance were measured by adding the second locus to the ANOVA or ANCOVA model according to Weller et al. (1988):

$$
\begin{aligned}
Y_{i j k l}= & \mu+\alpha_{j}+\beta_{k}+\gamma_{l}+\alpha \beta_{j k}+\alpha \gamma_{j l}+\beta \gamma_{k l}+\alpha \beta \gamma_{j k l} \\
& +c\left(X_{i j k l}-X\right)+\varepsilon_{i j k},
\end{aligned}
$$

where $\gamma_{l}$ is the portion of $Y_{i j k l}$ attributable to genotype at the second locus and $\alpha \beta_{j k}, \alpha \gamma_{j l}, \beta \gamma_{k l}$ and $\alpha \beta \gamma_{j k l}$ are the various interaction terms. Epistasis would be indicated by a significant $\alpha \gamma_{j l}$ term.

\section{Results}

\section{Single-locus segregation}

Single-locus allelic segregation could be observed in at least one progeny group for 24 of the 65 loci screened. One mutant allele was observed at each of two microsatellite loci, Omy $77 D U$ and $S s a 14 D U$, in a possible 484 and 720 meioses, respectively. This represents a mutation rate of 0.20 per cent at Omy77DU and 0.14 per cent at Ssa14DU per microsatellite locus, which is within the range of previously reported rates (Huang et al., 1992). However, this represents a mutation rate of $5 \times 10^{-4}$ (4233 possible germline transmissions) across all microsatellite loci, which suggests a high level of germline stability for this collection of microsatellite loci.
Ten deviations from Mendelian expectations at single loci were detected with a $P<0.05$. After the sequential Bonferroni correction only two remained significantly different from a 1:1 allelic segregation: Ssa $4 D U$ in sire 91-1 in lot 25 and $O m y 105 D U$ in sire 91-1 in lot 22 ( $G_{1}=11.32$ and 9.94, respectively). Four of the 10 deviations occurred in the segregation of alleles in the sire 91-1 when mated to dam 88-1 (lot 25) representing 27 per cent of loci tested for single-locus segregation in the sire of this cross. This degree of single-locus deviation may indicate nonviability of lot 25 backcross progeny possessing particular combinations of alleles at these loci or associated chromosomal regions. However, 10 deviations from single-locus segregation with a $P<0.05$ account for $\approx 13$ per cent of all single-locus segregations in this study. This value is slightly higher than that previously published for cases where distinct gametic or progeny nonviability has not been observed (10 per cent in tepary bean; Garvin \& Weeden, 1994). Sex segregation in lots 22 and 25 gave an equal assortment of males and females.

\section{Linkage analysis}

Seven pairs of marker loci showed linkage associations with a LOD score greater than 3.0 (Table 1). The association between $S I D H P-3^{*}$ and $m M E P-2^{*}$ (linkage group 5L) has been previously reported (May \& Johnson, 1990). Two pairs of marker loci had LOD scores between 2.0 and 3.0, which is suggestive of linkage.

In one out of three cases where alleles at Omy207UoG and $m I D H P-2 *$ are segregating in the progeny of sire 91-1, a potential distant linkage association was detected (lot 22-37.19 cM, LOD = 1.74, data not shown). Danzmann (unpublished) detected significant linkage between maternal alleles at $m I D H P-2^{*}$ and the RAPD locus UBC66-0.86 $(27.20 \mathrm{cM})$ in a 1992 rainbow trout cross. In light of the tight linkage between Omy207UoG and UBC66-0.86 (Table 1), a distant classical linkage association between Omy207UoG and $m I D H P-2^{*}$ (linkage group 15L) is suggested.

\section{Quantitative trait analysis}

We analysed the $(\mathrm{H} \times(\mathrm{H} \times \mathrm{L}))$ families separately because lot 41 backcross progeny were more tolerant to the upper lethal temperature challenge than lot 22 backcross progeny (Wilcoxon signed ranks test; $P<0.001)$. Also, the observed ET of thermal tolerance were much greater in the backcross progeny derived from the two high temperature

(c) The Genetical Society of Great Britain, Heredity, 80, 143-151. 
Table 1 Tests of linkage among marker loci in three rainbow trout half-sib families

\begin{tabular}{|c|c|c|c|c|c|c|c|}
\hline \multirow[b]{2}{*}{ Loci } & \multirow{2}{*}{$\begin{array}{c}\text { Informative } \\
\text { parent } \\
\text { (family) }\end{array}$} & \multicolumn{4}{|c|}{ Observed progeny genotypes } & \multirow{2}{*}{$\begin{array}{l}\text { LOD } \\
\text { score }\end{array}$} & \multirow{2}{*}{$\begin{array}{l}\theta \pm \mathrm{SE} \\
(\mathrm{cM})\end{array}$} \\
\hline & & $A^{\prime} B$ & $A B^{\prime}$ & $A^{\prime} B$ & $A^{\prime} B^{\prime}$ & & \\
\hline \multirow[t]{3}{*}{ Omy301UoG to OmyFGT2TUF } & Dam (lot 22) & 57 & 0 & 2 & 61 & 31.71 & $1.67 \pm 1.17$ \\
\hline & Dam (lot 25) & 51 & 2 & 2 & 49 & 23.94 & $3.85 \pm 1.89$ \\
\hline & Dam (lot 41) & 64 & 15 & 14 & 49 & 11.53 & $20.42 \pm 3.38$ \\
\hline \multirow[t]{2}{*}{$s I D H P-3 *$ to $O m y 272 / 2 U o G$} & Sire (lot 25) & 46 & 0 & 0 & 57 & 31.01 & 0 \\
\hline & Dam (lot 25) & 35 & 14 & 20 & 34 & 2.63 & $33.01 \pm 4.63$ \\
\hline \multirow[t]{4}{*}{ Omy301UoG to Omy325UoG } & Sire (lot 22) & 64 & 1 & 2 & 53 & 30.03 & $2.50 \pm 1.43$ \\
\hline & Dam (lot 22) & 50 & 10 & 13 & 47 & 10.66 & $19.17 \pm 3.59$ \\
\hline & Sire (lot 41) & 51 & 14 & 16 & 57 & 10.16 & $21.74 \pm 3.51$ \\
\hline & Dam (lot 41) & 41 & 24 & 23 & 50 & 3.10 & $34.06 \pm 4.03$ \\
\hline \multirow[t]{2}{*}{ OmyFGT2TUF to Omy325UoG } & Dam (lot 22) & 50 & 11 & 10 & 50 & 12.17 & $17.36 \pm 3.44$ \\
\hline & Dam (lot 41) & 48 & 16 & 15 & 58 & 9.43 & $22.63 \pm 3.57$ \\
\hline$O m y 2 D U$ to $S s a 4 D U$ & Dam (lot 22) & 48 & 23 & 16 & 29 & 2.75 & $33.62 \pm 4.39$ \\
\hline OmyFGT3TUF to Ssa14DU & Dam (lot 22) & 44 & 13 & 28 & 32 & 2.31 & $35.04 \pm 4.41$ \\
\hline
\end{tabular}

LOD values greater than 3.0 are significant, those between 2.0 and 3.0 are suggestive of linkage.

$A B, A B^{\prime}, A^{\prime} B$ and $A^{\prime} B^{\prime}$ represent the four possible allelic combinations in the progeny inherited from the informative parent.

$\theta$ represents the map distance in centimorgans $(\mathrm{cM})$ between linked loci.

tolerance females (lots 22 and 41) compared to the low temperature tolerance female (lot 25) (Table 2), presumably because these females possessed higher temperature tolerance QTL alleles.

Two-way ANOVA/ANCOVAs for upper temperature tolerance indicated that genotypes at eight loci were associated with differences in upper temperature tolerance $(P<0.05)$ (Table 3$)$. There was no significant genotype $\times$ experiment interaction in any of these eight analyses. The number of loci tested for QTL association in each parent within each family (followed by the Bonferroni corrected $P$ threshold) was: sire 91-1 (lot 22) - 11 loci (0.0045); dam 88-5 (lot 22) - 13 loci (0.0038); sire 91-1 (lot 25) - 15

Table 2 Descriptive statistics for the trait of upper temperature tolerance (ET in minutes) and body size (fork length in $\mathrm{mm}$ ) in three rainbow trout half-sib families

\begin{tabular}{lrrrrr}
\hline Family (cross-type) & $N$ & Mean & SE & Variance & Range \\
\hline ET (min) & & & & & \\
Lot 22 $(\mathrm{H} \times(\mathrm{H} \times \mathrm{L}))$ & 121 & 162.6 & 7.3 & 6515.6 & $20-350$ \\
Lot 25 $(\mathrm{L} \times(\mathrm{H} \times \mathrm{L}))$ & 104 & 80.4 & 6.8 & 4879.5 & $-2^{1}-309$ \\
Lot 41 $(\mathrm{H} \times(\mathrm{H} \times \mathrm{L}))$ & $88^{2}$ & 277.8 & 11.1 & 10786.2 & $54-440$ \\
Fork length $(\mathrm{mm})$ & & & & & \\
Lot 22 $(\mathrm{H} \times(\mathrm{H} \times \mathrm{L}))$ & 121 & 170.7 & 1.5 & 275.7 & $122-209$ \\
Lot 25 $(\mathrm{L} \times(\mathrm{H} \times \mathrm{L}))$ & 104 & 179.3 & 1.9 & 365.2 & $112-225$ \\
Lot 41 $(\mathrm{H} \times(\mathrm{H} \times \mathrm{L}))$ & $88^{2}$ & 120.4 & 1.5 & 210.6 & $91-153$ \\
\hline
\end{tabular}

${ }^{1}$ Negative values indicate progeny that have lost equilibrium prior to reaching the upper lethal temperature $\left(25.7^{\circ} \mathrm{C}\right)$.

${ }^{2}$ Descriptive statistics are only relevant for 88 of 144 progeny. 
Table 3 Results of two-way anOva/Ancovas (including experiment) testing associations in rainbow trout between genotype and upper temperature tolerance (ET in minutes) with a $P<0.05$

\begin{tabular}{lccccc}
\hline Locus & Parent (family) & $F$-ratio & $R_{\mathrm{G}}^{2}$ & Mean $_{\mathrm{Ar}}$ & Mean $_{\mathrm{Ad}}$ \\
\hline Omy325UoG & $88-30$ (lot 41) & $19.14^{* *}$ & 0.15 & 90.26 & 81.19 \\
Ssa14DU & $91-1$ (lot 41) & $15.44^{* *}$ & 0.13 & 77.19 & 77.92 \\
& $88-30($ lot 41) & 4.34 & 0.04 & 35.05 & 44.20 \\
Ssa85DU & $91-1$ (lot 41) & 6.72 & 0.07 & 57.56 & 53.82 \\
Omy77DU & $91-1($ lot 41) & 6.34 & 0.06 & 64.71 & 49.42 \\
OmyFGT2TUF & $88-30($ lot 41) & 6.00 & 0.06 & 53.07 & 49.73 \\
Omy301UoG & $91-1($ lot 25) & 5.80 & 0.05 & $27.82^{1}$ & $26.55^{1}$ \\
Omy272/1UoG & $88-1($ lot 25) & 4.56 & 0.04 & $26.80^{1}$ & $24.35^{1}$ \\
Omy105DU & $88-30($ lot 41) & 4.22 & 0.04 & 53.26 & 43.45 \\
\hline
\end{tabular}

$F$-ratio is that value calculated for the genotype component of the tested model.

$R_{\mathrm{G}}^{2}$ indicates the within-family variance in ET accounted for by genotype in the model.

Mean $_{\mathrm{Ar}}$ indicates the arithmetic mean difference in ET between genotypes whereas Mean $_{\mathrm{Ad}}$ indicates the adjusted mean difference in ET (from the two-way ANOVA/ANCOVA least squares mean) between genotypes.

**Significance after sequential Bonferroni correction of the initial $P<0.05$ threshold.

${ }^{1}$ Presented values are converted $\log _{10}$ transformed data used in the analysis.

loci (0.0033); dam 88-1 (lot 25) - 12 loci (0.0042); sire 91-1 (lot 41) - 14 loci (0.0036); and dam 88-30 - 11 loci $(0.0045)$. Only the association with Omy325UoG and Ssa14DU in lot 41 progeny was significant after the sequential Bonferroni correction for multiple tests. The $R^{2}$ values for these loci indicated that the total within-family variance in mean ET accounted for is 15 per cent and 13 per cent, respectively. Also, body size has an effect on upper temperature tolerance in the ANCOVAs for Omy325UoG and Ssa14DU $\left(F_{1,83}=5.171\right.$ and $F_{1,79}=4.275$, respectively).
A three-way ANCOVA with interaction was performed to determine if an epistatic relationship existed between the effects on upper temperature tolerance associated with $O m y 325 U o G$ and Ssa14DU in lot 41 (Table 4). This simultaneous analysis of both significant QTL associations provides better estimates of the individual QTL effects. The amount of within-family variance accounted for by this model at each locus was 13 per cent and 9 per cent, respectively. No significant interaction was seen between Omy325UoG and Ssa14DU $\left(F_{1,75}=0.597\right)$. No significant interaction was observed between any

Table 4 Three-way Ancova results to test for epistasis between the marker loci with significant or suggestive associations with upper temperature tolerance effects in the half-sib rainbow trout family lot 41

\begin{tabular}{lcrrr}
\hline Locus & SS (d.f.) & MS & F-ratio & $P$ \\
\hline Experiment & $91636(1)$ & 91636 & 13.9 & 0.000 \\
Omy325UoG & $107369(1)$ & 107368 & 16.3 & 0.000 \\
Ssa14DU & $73628(1)$ & 73628 & 11.2 & 0.001 \\
Experiment $\times$ Omy325UoG & $22744(1)$ & 22744 & 3.4 & 0.067 \\
Experiment $\times$ Ssa14DU & $8518(1)$ & 8518 & 1.3 & 0.259 \\
Omy325UoG $\times$ Ssa14DU & $3931(1)$ & 3931 & 0.6 & 0.442 \\
Experiment $\times$ Omy325UoG $\times$ Ssa14DU & $8638(1)$ & 8638 & 1.3 & 0.256 \\
Fork length & $34960(1)$ & 34960 & 5.3 & 0.024 \\
Residual & $493747(75)$ & 6583 & - & - \\
\hline
\end{tabular}

In the model presented, the maternal allele at $O m y 325 U o G$ accounts for 13 per cent of within-family variance $\left(R_{\mathrm{G} 1}^{2}\right)$ and the paternal allele at Ssa14DU accounts for 9 per cent of within-family variance $\left(R_{\mathrm{G} 2}^{2}\right)$ in mean ET.

(C) The Genetical Society of Great Britain, Heredity, 80, 143-151. 
of the markers showing apparent and/or significant QTL associations. This strongly suggests that the effects of these QTL in lot 41 progeny are additive.

\section{Discussion}

\section{Location of possible QTL}

The two chromosomal regions associated with the microsatellite loci Omy325UoG and Ssa14DU appear to affect the quantitative trait of upper temperature tolerance. We are aware of only a few other cases where variation in molecular marker genotypes shows a significant association with a quantitative trait in salmonid fishes. For example, liver PGM-1* expression is associated with developmental rate and body size in rainbow trout (Allendorf et al., 1983).

The association between upper temperature tolerance and paternal alleles at Ssa14DU was only significant in lot $41(\mathrm{H} \times(\mathrm{H} \times \mathrm{L}))$ even though informative tests with the same sire were also made in lots $22(\mathrm{H} \times(\mathrm{H} \times \mathrm{L}))$ and $25(\mathrm{~L} \times(\mathrm{H} \times \mathrm{L}))$. The ET of lot 22 progeny with different paternal alleles showed differences in the same direction as those in lot $41\left(F_{1,107}=1.984, P=0.16\right)$. However, there is no indication of any such association in lot 25 $\left(F_{1,94}=0.189, P=0.664\right)$. The apparent discrepancy between families can be explained by significant epistatic interactions when paternal alleles at Ssa14DU combine with the genetic contribution of the three different dams (Danzmann et al., submitted). Allele 135 is associated with increased temperature tolerance in the $\mathrm{H} \times(\mathrm{H} \times \mathrm{L})$ backrosses, but has a lower mean temperature tolerance in the $\mathrm{L} \times(\mathrm{H} \times \mathrm{L})$ backcross.

The major QTL allele linked to Omy325UoG was only detected in the dam $88-30$ of lot 41 but not in the dam $88-5$ of lot 22; it was not possible to test accurately for this association in the dam of lot 25 as both parents had identical genotypes. The identification of a strong QTL allele in dam $88-30$ is not surprising given that this female was derived from the line selected for higher upper temperature tolerance. Not all QTL alleles conferring an enhanced upper temperature tolerance will be monomorphic after three generations of selection, and therefore several QTL regions may display polymorphisms. Thus, individuals in the high selected line may differ in their QTL alleles.

The magnitude of the effect exhibited by the proposed QTL (13 per cent and 9 per cent of the within-family variance) in this study is similar to that reported elsewhere. These QTL would therefore explain 22 per cent of the additive genetic variance in upper temperature tolerance. Other studies have found that QTL range widely in the amount of their effect, accounting for $0.25-88.3$ per cent of the variance in the character of study. However, the mean effect of a QTL is generally 10 per cent of total phenotypic variance (Paterson et al., 1988; Weller et al., 1988).

\section{Expansion of the salmonid linkage map}

We have added six significant linkage associations to the salmonid map, suggested the presence of two other associations, and supported the previously reported association between $S I D H P-3^{*}$ and $m M E P$ $2^{*}$ in three half-sib rainbow trout crosses. However, the association between $O m y 2 D U$ and Ssa4DU (Table 1) does not appear to be supported, especially as the segregation of paternal alleles at these two loci shows no evidence of linkage in the three crosses tested. In addition, no evidence of linkage between alleles at these two loci was obtained from dam 88-30 in lot 41. The eight supported associations reported in Table 1 cluster into four linkage groups (Fig. 1) with the addition of a potential distant association between $m I D H P-2^{*}$ and $O m y 207 U o G$ (LOD $=1.74$, data not shown). The extent of linkage between Omy207UoG and UBC66-0.86 and the data collected by Danzmann (unpubl.) strongly suggest an association between these three loci. Also, as $m I D H P-2^{*}$ has been mapped to linkage group 15 of the composite salmonid linkage map (May \& Johnson, 1990), Omy207UoG and UBC66-0.86 may be located in this group as well.

\section{Differences in recombination rate}

Map distances presented in Fig. 1 are based exclusively on the recombination rates observed between cosegregating, maternally inherited alleles, with the exception of the map distance presented for the association between Omy207UoG and UBC66-0.86. This distance is based on the segregation of paternal alleles as there were no segregating maternal alleles observed for UBC66-0.86 in any of these crosses. The predominant use of female map distances is consistent with May \& Johnson (1990). Map distances in female salmonids are greater than those in males (see Table 1), a result consistent with other vertebrate species (cattle - Barendse et al., 1994; pigs - Ellegren et al., 1994). However, the difference in distance between the male and female map appears more extreme in the salmonids. From the linkage data presented by May \& Johnson (1990) 

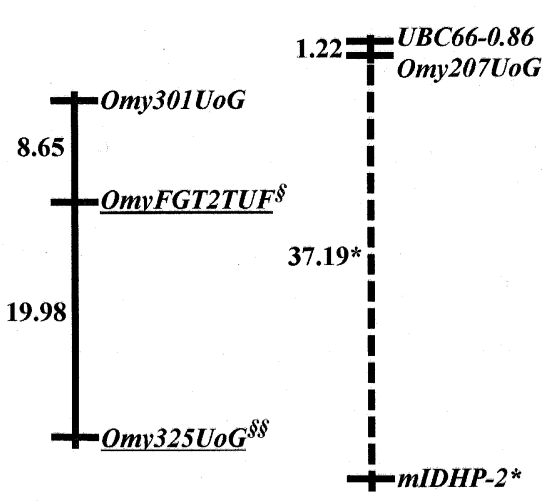

$4 \mathrm{cM}$

the ratio of female:male total map length is 2.1:1. Analagous ratios for cattle, pig and human maps are 1.2:1, 1.4:1 and 1.6:1, respectively, (Barendse et al., 1994; Ellegren et al., 1994; Dib et al., 1996). The cause of this extreme difference in distance among the salmonids is believed to be the formation of tetrads by homeologous chromosomes (ancestral homologues) tolerated in males. This may significantly constrain the recombination which can occur between loci on homologous chromosomes (Wright et al., 1983). Therefore, the female map distance is more likely to be representative of the physical distance existing between two loci in salmonid fishes.

We also found great differences in recombination rate between loci for alleles inherited from different dams and between the alleles inherited from sire 91-1 when crossed to different dams. These differences were of similar magnitude in both sexes. In lot 22 , both parents had lower recombination rates between the loci Omy301UoG, OmyFGT2TUF and Omy325UoG than in lot 41 (Table 1). As these differences are also observed between paternal alleles in families sired by the same male, individual differences in recombination would not adequately explain these findings. They may be a result of gametic incompatibility or postzygotic inviability caused by selection against particular allelic combinations within this chromosomal region.

Our results show interesting differences in QTL expression and inter- as well as apparent intraindividual differences in recombination rates in salmo-
Fig. 1 Significant $(\mathrm{LOD}>3.0)$ and suggested $(3.0>$ LOD $>2.0)$ linkage associations and associated quantitative trait loci (QTL) from three half-sib rainbow trout families. Map distances are based exclusively on average recombination rates between maternal alleles with the exception of the map distance between UBC66-0.86 and Omy207UoG which is based on the segregation of paternal alleles. An asterisk indicates an association that is not significant or suggested by the present data but is supported by other work (Danzmann, unpubl.). Solid lines indicate significant linkage associations and dashed lines indicate suggestive linkage associations. Underlined loci are those demonstrating an association with a QTL: § indicates a QTL association with a $P<0.05$ and $\S \S$ indicates a QTL association with a $P$ less than the sequential Bonferroni corrected 0.05 threshold. nid fishes. These findings raise important questions about the general application of linkage maps, especially in salmonids, and of the QTL associations found within these maps.

\section{Acknow ledgements}

We thank Mike Gatt for work on genomic library development and sequencing in the construction of microsatellite primers first published in this study. We also thank Bill Sloan and Bill Martin for assistance in the collection of phenotypic and allozyme data, Adrienne Zagar for assistance in the collection of microsatellite data, and Jonathan Wright and Roger Doyle for the provision of some microsatellite primers. This work was supported by grants from the Natural Sciences and Engineering Research Council Strategic Grant Program no. 230 (STR0135325 and STR0181211) to R. Danzmann.

\section{References}

Allendorf, F. W. AND THORgAARD, G. H. 1984. Tetraploidy and the evolution of salmonid fishes. In: Turner, B. J. (ed.) Evolutionary Genetics of Fishes, pp. 1-53. Plenum Press, New York.

ALLENDORF, F. W., MITCHELL, N., RYMAN, N. AND STÅHL, G. 1977. Isozyme loci in brown trout (Salmo trutta L.): detection and interpretation from population data. Hereditas, 86, 179-190.

ALLENDORF, F. W., KNUDSEN, K. L. AND LEARY, R. F. 1983. Adaptive significance of differences in the tissue-

(C) The Genetical Society of Great Britain, Heredity, 80, 143-151. 
specific expression of a phosphoglucomutase gene in rainbow trout. Proc. Natl. Acad. Sci. U.S.A., 80, $1397-1400$.

BARDAKCI, F. AND SKIBINSKI, D. O. F. 1994. Application of the RAPD technique in tilapia fish: species and subspecies identification. Heredity, 73, 117-123.

BARENDSE, W., ARMitAGE, S. M., KoSSAREK, L. M., SHALOM, A., KiRKPATRICK, B. W., RYAN, A. M. ET AL. 1994. A genetic linkage map of the bovine genome. Nature Genet., 6, 227-235.

BOtSTEIN, D., WHITE, R. L., SKOLNICK, M. AND DAVIS, R. W. 1980. Construction of a genetic linkage map in man using restriction fragment length polymorphisms. Am. J. Hum. Genet., 32, 314-331.

Dib, C., Faure, S., Fizames, C., SAmson, D., DRouot, N., VIGNAL, A. ET $A L$. 1996. A comprehensive genetic map of the human genome based on 5,264 microsatellites. Nature, 380, 152-154.

ELLEGREN, H., CHOWDHARY, B. P., JOHANSSON, M., MARKLUND, L., FREDHOLM, M., GUSTAVSSON, I. AND ANDERSON, L. 1994. A primary linkage map of the porcine genome reveals a low rate of genetic recombination. Genetics, 137, 1089-1100.

ESTOUP, A., PRESA, P., KRIEG, F., VAIMAN, D. AND GUYOMARD, R. 1993. $(\mathrm{CT})_{\mathrm{n}}$ and $(\mathrm{GT})_{\mathrm{n}}$ microsatellites: a new class of genetic markers for Salmo trutta L. (brown trout). Heredity, 71, 488-496.

FADER, S. C., YU, Z. AND SPOTILA, J. R. 1994. Seasonal variation in heat shock proteins (hsp-70) in stream fish under natural conditions. J. Therm. Biol., 19, 335-341.

FRY, F. E. J. 1971. The effect of environmental factors on the physiology of fish. In: Hoar, W. S. and Randall, D. J. (eds) Fish Physiology, vol. VI, Environmental Relations and Behaviour, pp. 1-97. Academic Press, New York.

GARVIN, D. F. AND WEEDEN, N. F. 1994. Genetic linkage between isozyme, morphological and DNA markers in tepary bean. J. Hered., 85, 273-278.

GERLACH, G.-F., TURAY, L., MALIK, K. T. A., LIDA, J., SCUTT, A. AND GOLDSPINK, G. 1990. Mechanisms of temperature acclimation in the carp: a molecular biology approach. Am. J. Physiol., 259, R237-R244.

HARTLEY, S. E. 1987. The chromosomes of salmonid fishes. Biol. Rev., 62, 197-214.

HUANG, T., COTTINGHAM, R. J., LEDBETTER, D. AND ZOGHBI, H. 1992. Genetic mapping of four dinucleotide repeat loci, DXS453, DXS458, DXS454, and DXS424 on the $\mathrm{X}$ chromosome using multiplex polymerase chain reaction. Genomics, 13, 375-380.

IHSSEN, P. E. 1986. Selection of fingerling rainbow trout for high and low tolerance to high temperature. Aquaculture, 57, 370 .

JACKSON, T. R. 1995. Linkage Analysis of Molecular Markers and a Search for Quantitative Trait Loci for Upper Temperature Tolerance in Rainbow Trout (Oncorhynchus mykiss). M.Sc. Thesis, University of Guelph, Guelph, ON.

MATHER, к. 1951. The Measurement of Linkage in Heredity, 2nd edn. John Wiley and Sons, New York.
MAY, B. AND JOHNSON, K. R. 1990. Composite linkage map of salmonid fishes (Salvelinus, Salmo, Oncorhynchus). In: O'Brien, S. J. (ed.) Genetic Maps: Locus Maps of Complex Genomes, pp. 151-159. Cold Spring Harbor Laboratory Press, Cold Spring Harbor, NY.

McCONNELL, S. K., O'REILLY, P., HAMILTON, L., WRIGHT, J. M. AND BENTZEN, P. 1995. Polymorphic microsatellite loci from Atlantic salmon (Salmo salar): genetic differentiation of North American and European populations. Can. J. Fish. Aquat. Sci., 52, 1863-1872.

MORRIS, D. B., RICHARD, K. R. AND WRIGHT, J. M. 1996. Microsatellites from rainbow trout (Oncorhynchus mykiss) and their use for genetic study of salmonids. Can. J. Fish. Aquat. Sci., 53, 120-126.

O'CONNELL, M., DANZMANN, R. G., CORNUET, J.-M., WRIGHT, J. M. AND FERGUSON, M. M. 1997. Differentiation of rainbow trout populations in Lake Ontario and the evaluation of the stepwise mutation and infinite allele mutation models using microsatellite variability. Can. J. Fish. Aquat. Sci., 54, 1391-1399.

O'REILly, P. T., HAMILTON, L. C., McCONNELL, S. K. AND WRIGHT, J. M. 1996. Rapid analysis of genetic variation in Atlantic salmon (Salmo salar) by PCR multi-plexing of dinucleotide and tetranucleotide microsatellites. Can. J. Fish. Aquat. Sci., 53, 2292-2298.

PATERSON, A. H., LANDER, E. S., HEWITT, J. D., PETERSON, S., LINCOLN, S. E. AND TANKSLEY, S. D. 1988. Resolution of quantitative traits into Mendelian factors by using a complete linkage map of restriction fragment length polymorphisms. Nature, 335, 721-726.

PRODÖHL, P. A., TAGGART, J. B. AND FERGUSON, A. 1994. Single locus inheritance and joint segregation analysis of minisatellite (VNTR) DNA loci in brown trout (Salmo trutta L.). Heredity, 73, 556-566.

RICE, W. R. 1989. Analyzing tables of statistical tests. Evolution, 43, 223-225.

SAKAMOto, т., OKAMOto, N. AND IKEDA, y. 1994a. Dinucleotide repeat polymorphism of rainbow trout, FGT2. J. Anim. Sci., 72, 2765.

SAKAMOto, т., OKAMOto, N. AND IKeDA, y. 1994b. Dinucleotide repeat polymorphism of rainbow trout, FGT3. J. Anim. Sci., 72, 2766.

THORGAARD, G. H., ALLENDORF, F. W. AND KNUDSEN, K. L. 1983. Gene-centromere mapping in rainbow trout: high interference over long map distances. Genetics, 103, 771-783.

WELLER, J. I., SOLLER, M. AND BRODy, T. 1988. Linkage analysis of quantitative traits in an interspecific cross of tomato (Lycopersicon esculentum $\times$ Lycopersicon pimpinellifolium) by means of genetic markers. Genetics, 118, 329-339.

WRIGHT, J. E., JOHNSON, K. R., HOLLISTER, A. AND MAY, B. 1983. Meiotic models to explain classical linkage, pseudolinkage, and chromosome pairing in tetraploid derivative salmonid genomes. In: Rattazzi, M. C., Scandalios, J. G. and Whitt, G. S. (eds) Isozymes: Current Topics in Biological and Medical Research, pp. 239-260. Alan R. Liss, New York. 